\title{
Superoxide dismutase activity, lipid peroxide production and corpus luteum steroidogenesis during natural luteolysis and regression induced by oestradiol deprivation of the ovary in pseudopregnant rabbits
}

\author{
J. S. Hesla*, T. Miyazaki†, L. M. Dasko, E. E. Wallach and \\ A. M. Dharmarajan \\ Department of Gynecology and Obstetrics, The Johns Hopkins University School of Medicine, \\ Baltimore, MD 21205, USA
}

\begin{abstract}
Summary. The relationship of oxygen free radicals to corpus luteum function in rabbits was explored during various stages of pseudopregnancy, including natural and induced luteal regression. Induced luteolysis was achieved during mid-pseudopregnancy by removal of an oestradiol capsule placed at the onset of pseudopregnancy, which suppressed ovarian oestradiol production. Activity of manganese superoxide dismutase (Mn SOD) was significantly and positively correlated with ovarian progesterone production $(P<0 \cdot 01)$ throughout pseudopregnancy and during natural regression. Oestradiol deprivation for 12,24 or $72 \mathrm{~h}$ resulted in declines in Mn SOD activity and progesterone secretion, although $\mathrm{Mn}$ SOD rose and corpus luteum steroidogenesis was restored to normal when the capsule was replaced for $48 \mathrm{~h}$ before assessment, having been removed for $24 \mathrm{~h}$. Lipid peroxide and progesterone concentrations were not correlated, although a significant rise in lipid peroxides in the luteal tissue was detected after deprivation of oestradiol for $72 \mathrm{~h}$. Changes in progesterone production and Mn SOD activity were not associated with alterations in concentration of prostaglandin $F$ metabolite. These data suggest that Mn SOD may be involved in regulating function of the corpus luteum during pseudopregnancy in rabbits and that oxygen free radicals may play a role in regression of corpus luteum in this species.
\end{abstract}

Keywords: corpus luteum: rabbit; superoxide dismutase: progesterone; lipid peroxide

\section{Introduction}

Although ovarian function in pseudopregnant rabbits has been well characterized (Dharmarajan $e t$ al., 1989; Holt, 1989), the regulatory factors that influence growth, hormone production and regression of the corpus luteum remain to be clarified. Oestradiol is the primary luteotrophin in intact and hypophysectomized pseudopregnant rabbits; progesterone secretion declines dramatically when oestradiol support of the corpora lutea is withdrawn (Bill \& Keyes, 1983; Dharmarajan et al., 1991). The mechanism for this induced, premature regression of luteal function is not understood; recent data suggest that prostaglandins are not directly involved (Dharmarajan et al., 1989), but there is increasing evidence from studies in rats that an accumulation of toxic metabolites of oxygen may be associated with luteolysis (Behrman \& Preston, 1989; Behrman \& Aten, 1991; Gatzuli et al., 1991; Riley \& Behrman, 1991; Sawada \& Carlson, 1989, 1991).

* Reprint requests.

†Present address: Department of Obstetrics and Gynecology, Ogikubo Hospital, Suginami-ku, Tokyo 167, Japan. 
An in vivo examination of the role of reactive oxygen species in cellular events is severely compromised by the extremely short half-lifes of these metabolites. One indirect approach frequently used to characterize free-radical mechanisms in physiological processes is to measure the highly specific inhibitor of the superoxide anion, superoxide dismutase (SOD). Superoxide dismutase is thought to be induced by reactive oxygen species (Dryer et al., 1980) and has been histochemically localized in rat ovary where it may play a role in regulating luteal function (Laloraya et al., 1988).

Few data have been published concerning the ovarian action of superoxide radicals in species other than rat, although one recent study in rabbits clearly demonstrated a role for superoxide in the mechanical process of ovulation (Miyazaki et al., 1991). The objectives of this investigation were to determine whether oxygen free radicals are involved in the regulation of the function of the corpus luteum in rabbits during pseudopregnancy and to assess the hypothesis that oestradiol influences luteal function by directly or indirectly promoting the production of free-radical scavengers. Corpus luteum SOD activity and lipid peroxide concentrations were measured and correlated with progesterone production at several points during the natural lifespan of the corpus luteum in pseudopregnancy. Because of its physiological role in the process of ovulation and corpus luteum regression in many animals, prostaglandin production was measured concurrently. The known requirement of oestradiol support for functional maintenance of the corpora lutea allowed for the development of an in vivo model to assess the effects of acute shifts in concentration of circulating oestradiol on production of free-radical scavengers during mid-pseudopregnancy.

\section{Materials and Methods}

\section{Animals}

Sexually mature New Zealand White female rabbits with a mean weight of $4.0 \mathrm{~kg}$ were used. The animals were caged individually for a minimum of 3 weeks under controlled light and temperature and given free access to water and Purina Rabbit Chow (Ralston-Purina Co., St Louis, MO, USA). Pseudopregnancy was induced by administration of human chorionic gonadotrophin via marginal ear vein (hCG, $100 \mathrm{iu}$; Pregnyl: Organon, Inc., West Orange, NJ, USA). The day of hCG injection was considered day 0 of pseudopregnancy. The selection of days of pseudopregnancy for study was based upon previous observations that progesterone secretion increases after administration of hCG to reach a maximum on day 11 and then declines to day 1 rates by day 18 (Dharmarajan et al., 1989).

\section{Treatment groups}

Experiment 1: natural luteal regression. Sixteen rabbits that received hCG on day 0 to render them pseudopregnant were studied. Laparotomy was performed on days $4,11,15$ and 20 of pseudopregnancy to obtain specimens of ovarian venous blood and luteal tissue.

Experiment 2: luteal regression induced by oestradiol deprivation. Eighteen animals were randomly assigned to one of six experimental groups (three per treatment group). On day 0 of pseudopregnancy, each rabbit had a single Silastic capsule (Dow-Corning Corp., Midland, MI, USA; $3 \mathrm{~cm}$ long, $3.35 \mathrm{~mm}$ i.d.) implanted s.c. beneath the base of the neck, which contained oestradiol ( $2 \mathrm{~cm}$ filled length; Sigma Chemicals, St Louis, MO, USA) or was empty (control rabbits) (Dharmarajan et al., 1991). On the tenth day of pseudopregnancy and after continuous subcutaneous administration of oestradiol, group 1 rabbits were subjected to laparotomy and blood and luteal tissue samples were collected. At the same stage of pseudopregnancy (day 10), the capsules in groups 2 and 3 were removed to initiate deprivation of oestradiol and the animals were subjected to laparotomy $12 \mathrm{~h}$ (group 2) and $24 \mathrm{~h}$ (group 3 ) thereafter. Animals in group 4 had the capsules removed on day 9 and laparotomy performed $72 \mathrm{~h}$ later (day 12). Group 5 rabbits had the oestradiol-filled capsules removed on day 9 of pseudopregnancy and reimplanted $24 \mathrm{~h}$ later, then underwent laparotomy on day 12 (48 $\mathrm{h}$ after capsule replacement). Control animals had the empty Silastic capsule removed on day 10 and laparotomy performed on day 11 .

\section{Sample collection}

The animals were anaesthetized with intravenous sodium pentobarbital $\left(32 \mathrm{mg} \mathrm{kg}^{-1}\right)$, given heparin sodium $\left(120 \mathrm{U} \mathrm{kg}^{-1}\right)$ for anticoagulation and then subjected to laparotomy. The anastomotic vessels to the ovaries were ligated with 4-0 silk suture. Each ovarian vein was isolated for $5 \mathrm{~mm}$. A small incision was made in the vessel to allow 
cannulation with bevelled polyethylene tubing (NewAge Industries, Willow Grove, PA, USA). Ovarian vein blood samples were obtained for determination of plasma progesterone, prostaglandin F metabolite (PGFM) and, in Expt 2, oestradiol. In addition, animals in Expt 2 had blood samples drawn from the marginal ear vein for measurement of peripheral oestradiol. After collection of the blood, the ovaries were excised. The corpora lutea were dissected free from the stroma and weighed individually. All tissues were frozen and stored at $-70^{\circ} \mathrm{C}$ for subsequent determinations of Mn SOD and lipid peroxide activity.

\section{Superoxide dismutase activity}

Manganese SOD (Mn SOD) activity in corpora lutea homogenates was measured by the inhibition of nitroblue tetrazolium (NBT) reduction by xanthine oxidase (Oberley \& Spitz, 1984). Tissues were homogenized with a TeflonPotter homogenizer in ice-cold potassium phosphate buffer $\left(0.05 \mathrm{~mol} 1^{-1}, \mathrm{w} / \mathrm{v}\right), \mathrm{pH} 7.8$, with $15-20$ strokes. Xanthine $\left(0.1 \mathrm{mmol}^{-1}\right.$; Sigma Chemical Co., St Louis, MO, USA) and xanthine oxidase (Boehringer Mannheim Biochemicals, Indianapolis, USA), adjusted to cause reduction of NBT at $0.015-0.025 \mathrm{U} \mathrm{mg}^{-1}$ protein min ${ }^{-1}$ at $560 \mathrm{~nm}$, were used to generate superoxide anion $\left(\mathrm{O}_{2}^{-}\right)$. NBT $\left(56 \mu \mathrm{mol} 1^{-1}\right.$; Sigma Chemical Co., St Louis, MO, USA) was added to compete with SOD for $\mathrm{O}_{2}{ }^{-}$. Diethylenetriamine pentaacetic acid ( 1 mmol l- ${ }^{-1}$; Mallinckrodt, Inc., Paris, KY, USA) was incorporated as metal chelator, and catalase (1.0 unit; Sigma Chemical Co., St Louis, MO, USA) was used to remove hydrogen peroxide $\left(\mathrm{H}_{2} \mathrm{O}_{2}\right)$. Sodium cyanide $\left(5 \mathrm{mmol} \mathrm{l}^{-1}\right)$ was added to inhibit copper-zinc SOD (Oberley \& Spitz, 1984). These reagents, contained in a $0.8 \mathrm{ml}$ solution, were added to $0.1 \mathrm{ml}$ of the tissue homogenate. NBT reduction was measured by the change in absorbance at $560 \mathrm{~nm}$. One unit of activity was defined as the amount that inhibited the rate of NBT reduction by $50 \%$. The values were standardized to units $\mathrm{mg}^{-1}$ protein.

Protein concentration in homogenates was determined by the method of Lowry et al. (1951) using a commercial kit (Sigma Chemical Co.).

\section{Lipid peroxide}

Lipid peroxidation in corpora lutea was assessed by the thiobarbituric (TBA) reaction, which measures the secondary product of peroxidation, malondialdehyde (MDA) (Ohkawa et al., 1979). Corpora lutea were homogenized with a Teflon-Potter homogenizer in ice-cold $1 \cdot 15 \% \mathrm{KCl}$ with $15-20$ strokes. To $0 \cdot 1 \mathrm{ml}$ of a $10 \%$ (w/v) tissue homogenate was added $0.2 \mathrm{ml}$ of $8.1 \%$ sodium dodecyl sulfate, $1.5 \mathrm{ml}$ of $20 \%$ acetic acid solution adjusted to $\mathrm{pH} 3.5$ with $\mathrm{NaOH}$ and $1.5 \mathrm{ml}$ of $0.8 \%$ aqueous solution of TBA (Sigma Chemical Co., St Louis, MO, USA). The mixture was heated in boiling water for $60 \mathrm{~min}$. After cooling, $1.0 \mathrm{ml}$ of distilled water and $5.0 \mathrm{ml}$ of a mixture of $n$-butanol and pyridine $(15: 1 \mathrm{v} / \mathrm{v})$ were added and the mixture was vigorously shaken. After centrifugation at $5000 \mathrm{~g}$ for $10 \mathrm{~min}$, the organic upper layer was removed and its absorbance at $532 \mathrm{~nm}$ was measured. 1,1,3,3-Tetramethoxypropane was used as an external standard, and the amount of lipid peroxidation was expressed as nmol MDA $\mathrm{g}^{-1}$ wet weight.

\section{Radioimmunoassays for progesterone, prostaglandin and oestradiol}

Concentrations of ovarian vein plasma progesterone and oestradiol were measured using a solid-phase kit (Diagnostic Products Co., Los Angeles, CA, USA) in which the steroid antibody is covalently bound to the inner surface of polypropylene assay tubes (Dharmarajan et al., 1989). All samples and standards (100 $\mu$ l) were assayed in duplicate. The sensitivity was $0.05 \mathrm{ng} \mathrm{ml}^{-1}$ and the intra- and interassay variations were 7.5 and $6.6 \%$, respectively, for progesterone and were 6.8 and $4.4 \%$, respectively, for oestradiol. Concentration of prostaglandin $F$ metabolite (PGFM) was measured by methods previously described (Dubin et al., 1979). The intraassay coefficient of variation was $<9 \%$ and samples from each day were assayed together to preclude error due to interassay variation.

\section{Statistical analysis}

Data were evaluated by analysis of variance with repeated measures followed by Duncan's multiple-range test. Two-group comparisons were made by Student's $t$ test. A probability of $<0.05$ was considered significant.

\section{Results}

\section{Experiment 1: natural luteal regression}

Ovarian venous plasma progesterone and PGFM. Progesterone concentration in ovarian venous plasma increased from day $4\left(492 \pm 150 \mathrm{ng} \mathrm{ml}^{-1}\right)$ to day $11(1107 \pm 135)$ and then declined to very low values by day 20 (228 \pm 64 ) (Fig. 1a). The concentration of PGFM in ovarian venous plasma was similar throughout the course of pseudopregnancy (Fig. 1b) and was not correlated with progesterone concentration. 

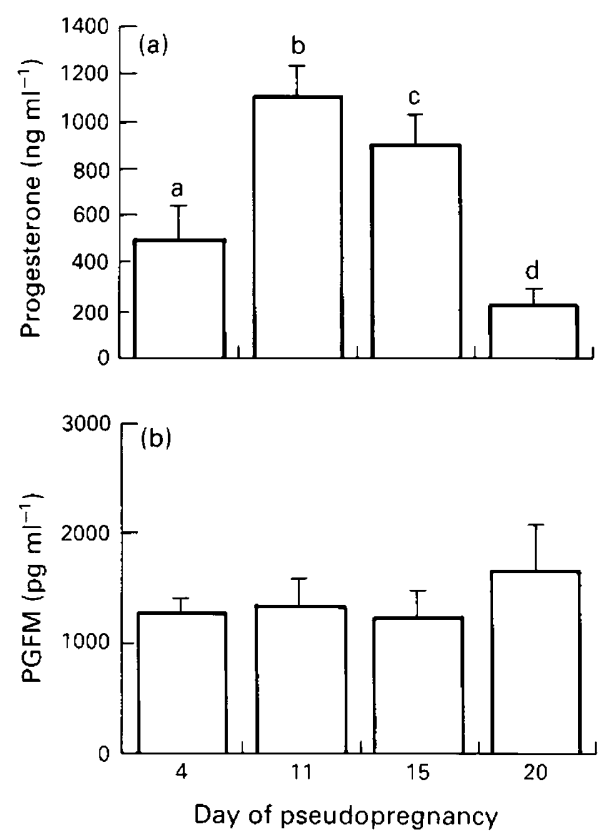

Fig. 1. Concentration of (a) ovarian venous progesterone and (b) prostaglandin F metabolite (PGFM), at days 4,11, 15 and 20 of pseudopregnancy in rabbits (Expt 1). Values with different superscripts were significantly different $(P<0 \cdot 01)$. There was no statistical difference among PGFM concentrations.

Activity of $M \boldsymbol{n}$ SOD. Activity of Mn SOD increased significantly from day $4\left(96 \pm 3 \mathrm{U} \mathrm{mg}^{-1}\right.$ protein) to day $11(178 \pm 39$ ), but then declined significantly by day 20 (34 \pm 11 ) (Fig. 2). The $\mathrm{Mn}$ SOD activity was significantly associated with progesterone production by the ovary $(r=0.687$; $P<0.01$ ), but was not correlated with PGFM concentration.

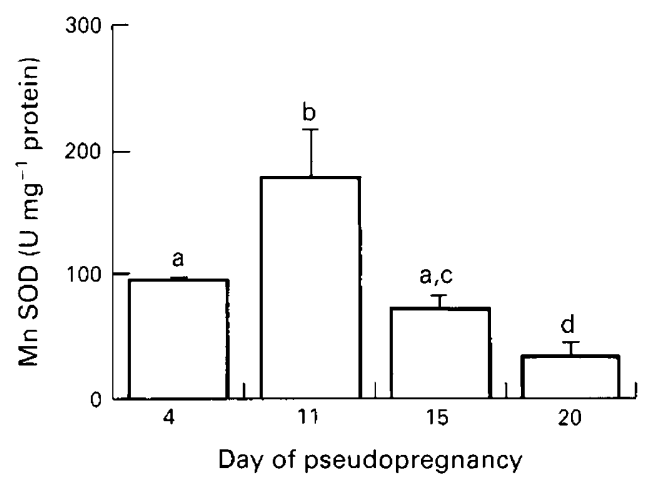

Fig. 2. Mean activity of manganese superoxide dismutase (Mn SOD) in corpora lutea on days $4,11,15$ and 20 of pseudopregnancy in rabbits (Expt 1). Values with different superscripts differed significantly $(P<0 \cdot 05)$.

Lipid peroxide. There was no consistent pattern of change in MDA concentration during the course of pseudopregnancy. The concentration on day $4\left(73 \pm 4 \mathrm{MDA}\right.$ nmol mg $\left.\mathrm{m}^{-1} \mathrm{protein}\right)$ was significantly $(P<0.01)$ higher than on day $11(60 \pm 3)$, day $15(53 \pm 4)$ and day $20(60 \pm 3)$. Although the concentration of lipid peroxide on day 15, when Mn SOD activity was highest, was 
lower than on any of the other days of pseudopregnancy, there was no significant correlation between lipid peroxide and Mn SOD activity. There was no correlation between lipid peroxide and PGFM concentrations.

\section{Experiment 2: luteal regression induced by oestradiol deprivation}

Endogenous oestradiol production. Oestradiol implants significantly suppressed endogenous oestradiol production during mid-pseudopregnancy. Ovarian venous oestradiol concentrations ranged from $295.0 \pm 39.0 \mathrm{pg} \mathrm{ml}^{-1}$ in control (sham implant) animals to $37.0 \pm 3.6 \mathrm{pg} \mathrm{ml}^{-1}$ in animals with intact oestradiol capsules at the time of laparotomy (group 1). The associated peripheral plasma concentrations of oestradiol were $17 \cdot 0 \pm 5 \cdot 0 \mathrm{pg} \mathrm{ml}^{-1}$ in control and $33 \cdot 6 \pm 5 \cdot 3 \mathrm{pg}$ $\mathrm{ml}^{-1}$ in group 1 animals. When oestradiol capsules were removed at 12,24 or $72 \mathrm{~h}$ before laparotomy (groups 2, 3 and 4) or were removed and then reimplanted (group 5), oestradiol concentrations in ovarian venous plasma were significantly higher than those of animals with intact capsules (group 1) $(P<0.05)$ (Fig. 3). Corresponding peripheral concentrations of oestradiol were $18 \cdot 7 \pm 2 \cdot 6,14 \cdot 0 \pm 1 \cdot 7,11 \cdot 6 \pm 0.9$ and $22 \cdot 6 \pm 1 \cdot 1 \mathrm{pg} \mathrm{ml}^{-1}$ for groups $2,3,4$ and 5 , respectively.

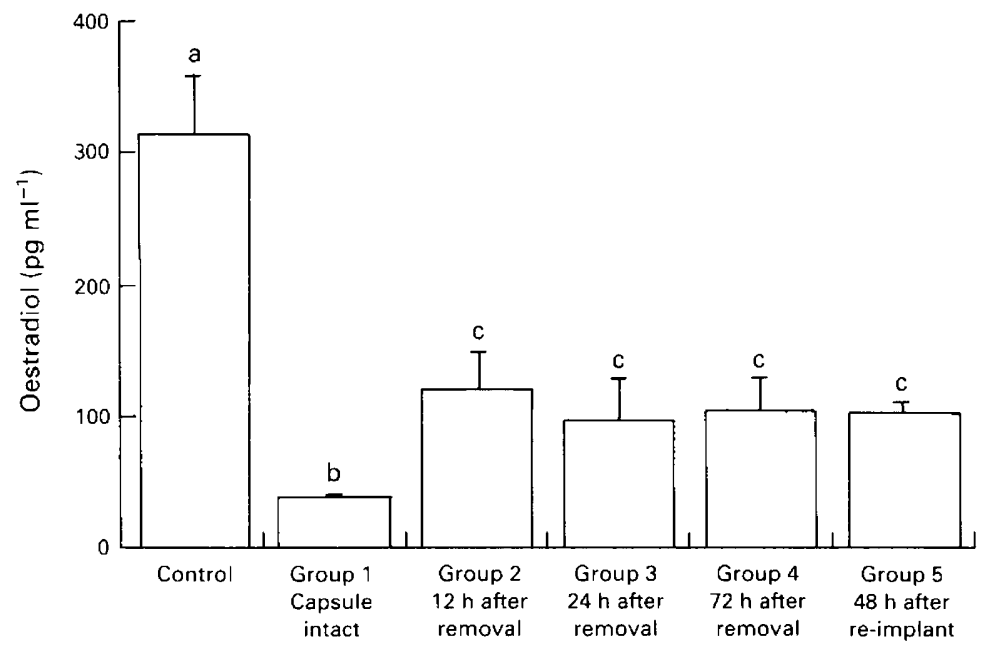

Fig. 3. Concentration of oestradiol in ovarian venous plasma of subcutaneous oestradioltreated and control rabbits (Expt 2$)$. Reduction was more pronounced $(P<0.01)$ when the capsules were in place at the time of blood sampling. Values with different superscripts were significantly different $(P<0 \cdot 01)$.

Progesterone production. There was no difference in ovarian venous progesterone concentrations on day 10 of pseudopregnancy between control and oestradiol-treated, capsule-intact animals (group 1). Progesterone concentrations had significantly decreased when ovarian vein blood was collected 12 (group 2), 24 (group 3) or $72 \mathrm{~h}$ (group 4) after capsule removal $(P<0.001$ ). However, when exogenous oestradiol support was reinstated for $48 \mathrm{~h}$ having been withdrawn for $24 \mathrm{~h}$ (group 5), progesterone concentrations approximated those measured in animals that had not been deprived of oestradiol (Fig. 4a).

Ovarian venous prostaglandin $\boldsymbol{F}_{2 \alpha}$ metabolite (PGFM). In contrast to its influence on progesterone production, oestradiol capsule placement, withdrawal with or without reimplantation had no effect on PGFM concentrations (Fig. 4b). There was no correlation between concentrations of progesterone and PGFM among the various subgroups. These findings were similar to those obtained in corpora lutea undergoing natural regression.

Activity of Mn SOD. Activity of Mn SOD was low in control animals on day 10 of pseudopregnancy (Fig. 5). The highest Mn SOD activity was in the corpora lutea of animals that had received 

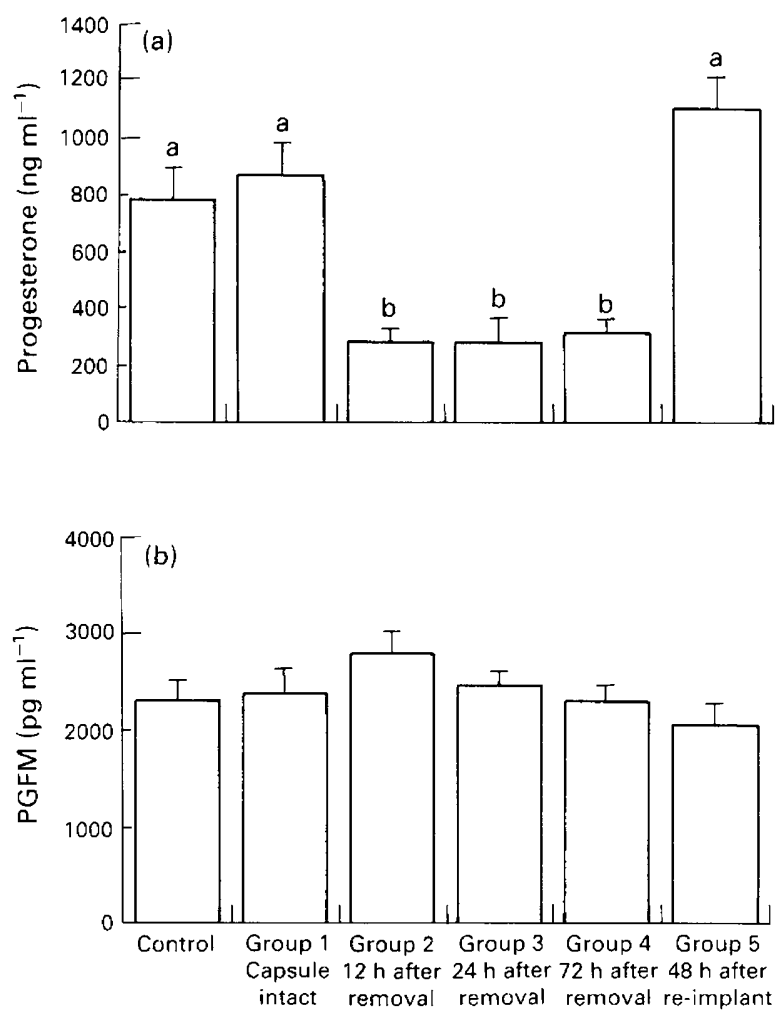

Fig. 4. Concentration of (a) ovarian venous progesterone and (b) prostaglandin F metabolite (PGFM), during luteal regression induced by oestradiol deprivation in rabbits (Expt 2). Values with different superscripts differed significantly $(P<0.001)$.

oestradiol capsule treatment throughout the course of pseudopregnancy (group 1). Withdrawal of exogenous oestradiol support before laparotomy resulted in serial decreases in Mn SOD activity at 12, 24 and $72 \mathrm{~h}$ after capsule removal. Mn SOD activity increased significantly after restoration of oestradiol capsule treatment in animals that had been deprived of exogenous oestradiol for $24 \mathrm{~h}$ during mid-pseudopregnancy (group 5, $P<0.01$ ).

Lipid peroxide. Oestradiol capsule implantation on day 0 of pseudopregnancy or capsule removal on day 9 or 10 did not affect lipid peroxide concentrations unless the animals were deprived of exogenous oestradiol for $72 \mathrm{~h}$ (Fig. 6), when they significantly increased $(P<0 \cdot 01)$. Reimplantation of the capsule for $48 \mathrm{~h}$ after $24 \mathrm{~h}$ of oestradiol deprivation resulted in higher lipid peroxide concentrations than those measured $72 \mathrm{~h}$ after withdrawal of exogenous oestradiol $(P<0.01)$.

\section{Discussion}

Reactive oxygen species may induce tissue injury through several mechanisms. Although $\mathrm{O}_{2}{ }^{-}$is charged, it can cross plasma membranes via anion channels, directly permeate defined lipid bilayers or gain access to intracellular sites as the uncharged $\mathrm{HO}_{2}{ }^{\circ}$ (Weiss, 1986). Hydrogen peroxide is a small, neutral molecule that has a permeability constant across membranes that is comparable to that of water (Chance et al., 1979). An oxidant attack on membrane, lipoprotein or albumin- 


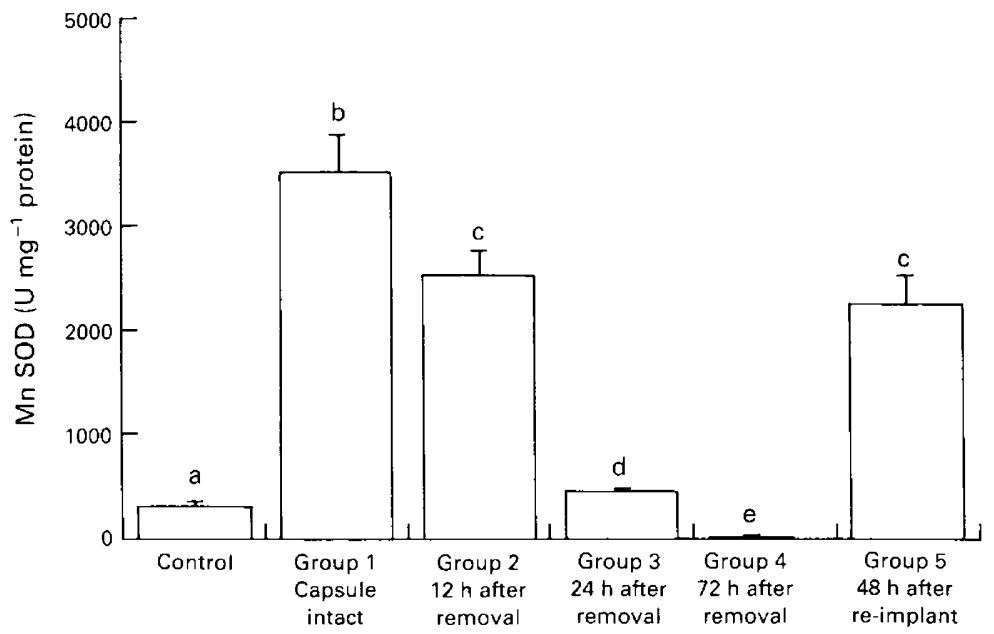

Fig. 5. Activity of manganese superoxide dismutase (Mn SOD) in corpora lutea (Expt 2) of rabbits. Activity was low in control, increased to maximum with continuous oestradiol treatment and decreased significantly after capsule removal $(P<0.01)$. Means within treatment group with different letter designations were significantly different $(P<0.01)$.

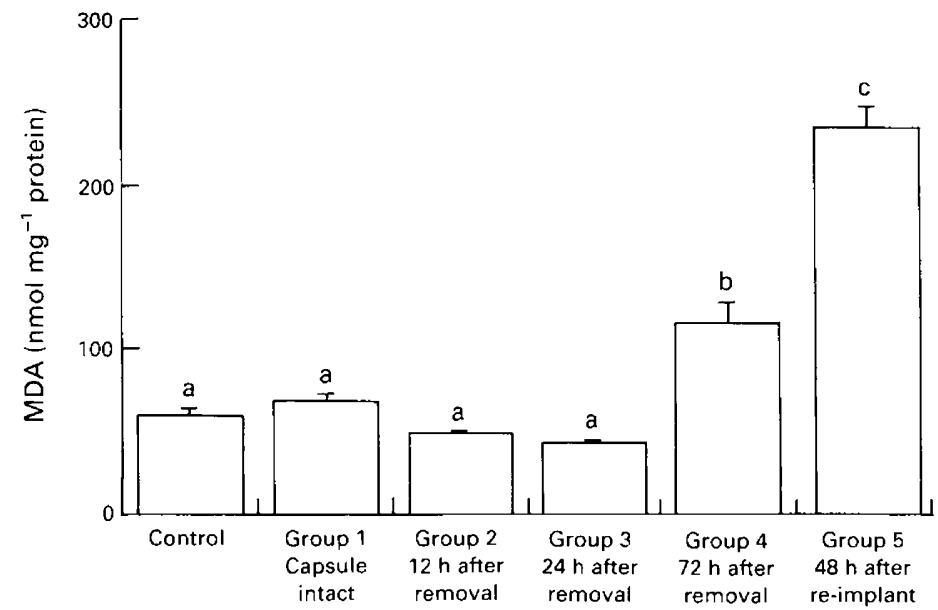

Fig. 6. Lipid peroxidation in corpora lutea of rabbits as assessed by malondialdehyde (MDA) concentration (Expt 2). Oestradiol capsule implantation or removal did not affect lipid peroxide levels $72 \mathrm{~h}$ after removal, at which time the level was significantly increased $(P<0.01)$. Reimplantation further increased lipid peroxide over that measured after $72 \mathrm{~h}$ of deprivation of exogenous oestradiol $(P<0.01)$. Values with different superscripts were significantly different $(P<0.01)$.

associated polyunsaturated fatty acids can initiate a complex cascade of events leading to the formation of reactive, unstable oxidants, long-lived toxic by-products, or biologically active inflammatory mediators that have the potential to propagate damage beyond the confines of the original focus. Furthermore, superoxides may directly alter protein and nucleic acid structure or function (Freeman \& Crapo, 1982).

In addition to the antioxidant compounds of tocopherol and ascorbate, the ovary contains SOD, catalase and glutathione peroxidase which enzymatically inactivate these highly toxic oxygen metabolites. Superoxide dismutase, the specific inhibitor of superoxide anion radical, has been isolated in several forms, which differ in their transition metal at the active centre and in their cell 
location. Copper-zinc SOD is primarily found in the cytosol and extracellular space, whereas $\mathrm{Mn}$ SOD is isolated in the mitochondrial matrix (Fridovich, 1986). The latter metalloenzyme is of particular relevance to corpus luteum function, for oxygen free radicals are produced not only by leucocytes but also by the mitochondrial electron-transport system and cytochrome $\mathrm{P} 450_{\mathrm{sec}}$ (Freeman \& Crapo, 1982; Weiss, 1986). Since cytochrome $\mathrm{P} 450_{\mathrm{scc}}$ is a key enzyme in progesterone synthesis, the reactive oxygen species created during the process of steroidogenesis may cause local damage and decrease steroidogenesis if not detoxified by SOD and other scavengers.

The presence of superoxide anions can induce both $\mathrm{Cu}-\mathrm{Zn}$ SOD and Mn SOD (Dryer et al., 1980), although in vitro studies have demonstrated that, in very high concentrations, $\mathrm{H}_{2} \mathrm{O}_{2}$ or a combination of $\mathrm{O}_{2}{ }^{-}$and $\mathrm{H}_{2} \mathrm{O}_{2}$ may inhibit the activity of SOD (Sinet \& Garber, 1981). In addition, the toxic hydroxyl radical may be produced by the Haber-Weiss reaction when $\mathrm{H}_{2} \mathrm{O}_{2}$, the end-product of SOD, reacts with $\mathrm{O}_{2}{ }^{-}$in the presence of iron (Fridovich, 1986). Without the presence of sufficient activity of the cytosolic enzyme, catalase, $\mathrm{H}_{2} \mathrm{O}_{2}$ generated in the dismutation reaction could itself inhibit progesterone production (Riley \& Behrman, 1991). Recent data suggest that $\mathrm{H}_{2} \mathrm{O}_{2}$ may affect progesterone synthesis by blocking the transfer of intracellular cholesterol to mitochondria or the translocation of cholesterol across the outer mitochondrial membrane (Behrman \& Aten, 1991).

The results of this study demonstrate the existence of a dependent relationship between $\mathrm{Mn}$ SOD activity and progesterone secretion in both natural luteolysis and regression induced by oestradiol deprivation. Concentrations of Mn SOD and progesterone production were high on day 11 of pseudopregnancy in the animals studied in Expt 1 . The significant decline in Mn SOD activity on days 15 and 20 was matched by a fall in progesterone production by the ovary. In the capsule model, oestradiol deprivation of the corpus luteum for 12 or more hours at mid-pseudopregnancy resulted in the expected fall in progesterone secretion (Dharmarajan et al., 1991), but also a precipitous drop in measured SOD. This association between SOD and corpus luteum function is consistent with the hypothesis that very high concentrations of oxygen free radicals may be present at the end of the life span of the corpus luteum which inactivate the cellular defences provided by SOD, promote tissue damage and further reduce the availability of protective enzymes such as SOD. Replacement of the oestradiol capsule after temporary withdrawal of exogenous hormonal support led to a rise in Mn SOD activity and reversal of functional regression, which gives further credence to the proposed relationships described.

Very low, yet stable, concentrations of progesterone were detected in the ovarian vein at 12, 24 and $72 \mathrm{~h}$ after removal of the oestradiol capsule, despite a continued decline in Mn SOD activity. The corpus luteum may have a reserve capacity for progesterone synthesis during this period of structural regression. Recent data from our laboratory have demonstrated that, after unilateral luteectomy or oophorectomy in pseudopregnant rabbits, ovarian venous progesterone concentration and progesterone secretion rates in the intact ovary increased to nearly $70 \%$ above their normal values (Dharmarajan et al., 1992). Hence, given the appropriate stimulus, luteal tissue may react to alterations in the hormonal milieu by mechanisms that attempt to sustain steroid secretion.

One process by which oestradiol may regulate luteal steroidogenic function in rabbits is through direct or indirect stimulation of free-radical scavengers. Continuous subcutaneous administration of oestradiol during early and mid-pseudopregnancy yielded a supraphysiological concentration of circulating plasma oestradiol and suppressed ovarian follicular production of oestradiol. The corpus luteum responded to this high oestradiol stimulation with a significant increase in luteal SOD activity, compared with control animals. The decline in exogenous circulating oestradiol after capsule removal led to partial recovery of ovarian follicular oestradiol production, but the overall diminution in oestradiol stimulation of the corpus luteum that occurred was associated with a fall in SOD activity over time. With restoration of oestradiol support after $24 \mathrm{~h}$ of depletion, SOD activity again rose, suggesting a dependent relationship.

In contrast to the data supporting a role for reactive oxygen species in functional luteolysis of pseudopregnant rabbits, the lack of significant change in prostaglandin metabolites during natural 
regression or that induced by oestradiol depletion suggests that prostaglandins do not play a primary role in luteolysis in rabbits. This corroborates the results of an earlier study where prostaglandin concentrations were measured in the tissues and in vitro perfusates of ovaries in late pseudopregnancy (Dharmarajan et al., 1989). The lack of correlation between the activity of the free-radical scavenger and prostaglandin metabolites would have been impossible to demonstrate if luteolysis had been initiated by prostaglandin administration rather than oestradiol deprivation. The use of prostaglandins may have created conditions that are not necessarily characteristic of natural luteolysis, for complex interactions exist among reactive oxygen species and the products of the lipoxygenase and cyclooxygenase pathways (Hemler et al., 1979; Parente, 1982).

An increased production of lipid peroxide was not noted in corpora lutea obtained during late pseudopregnancy, but, in the oestradiol deprivation model, luteal tissue lipid peroxide increased if the steroid capsule had been removed $72 \mathrm{~h}$ before sampling. This rise was not seen $24 \mathrm{~h}$ after capsule removal, although the decline in progesterone secretion had occurred by this time. Previous data concerning natural and prostaglandin-induced luteal regression in rats revealed that lipid peroxides increased after the initial decline in progesterone secretion was measured (Sawada \& Carlson, 1985, 1991). This temporal relationship suggests that lipid peroxidation is not responsible for initiating the functional changes associated with luteolysis, although membrane breakdown is an important feature of regression.

High concentrations of lipid peroxide were noted in animals of group 5 that experienced oestradiol deprivation followed by restoration of exogenous oestradiol support for $48 \mathrm{~h}$ before collection of corpora lutea. The reason is not readily apparent, but may be associated with an impaired ability of the luteal cell that had been previously damaged by oestradiol deprivation to detoxify reactive oxygen species. The heightened metabolic state of rabbit mitochondria that occurred with replacement of the major luteotrophic hormone, oestradiol, caused a proportional increase in production of $\mathrm{O}_{2}{ }^{-}$and $\mathrm{H}_{2} \mathrm{O}_{2}$ (Dryer et al., 1980). Nevertheless, the activity of $\mathrm{Mn}$ SOD did not approximate to that measured in animals receiving continuous oestradiol support and may reflect insufficient scavenging ability to prevent lipid oxidation. This hypothesis requires further investigation.

The results from the present study demonstrate a relationship between oestradiol concentration, Mn SOD activity and progesterone production in corpora lutea of pseudopregnant rabbits undergoing natural luteolysis and demise induced by depletion of oestradiol. A decline in antioxidant capability of the regressing corpus luteum may result in increased local concentrations of oxygen free radicals, which stimulate functional and structural regression. If so, it is achieved through mechanisms that do not result in heightened production of prostaglandin $F$ metabolites. The association between changes in luteotrophic stimulation by oestradiol and Mn SOD activity suggests that oestradiol may regulate corpus luteum steroidogenesis through this superoxide scavenger, which is primarily localized to the mitochondrial matrix of cells.

This work was supported by NIH Grant HD-19430, NIH Population Center Grant HD-06268, the SmithKline Beecham Fellowship (T. Miyazaki), and the Rockefeller Foundation (A. M. Dharmarajan and L. M. Dasko). We thank G. B. Bulkley for advice in study design and methods and F. Karas for secretarial assistance with preparation of this manuscript. The data were presented in part at the 72nd Annual Meeting of the Endocrine Society, Atlanta, GA, USA, 20-23 June 1990.

\section{References}

Behrman, H.R. \& Aten, R.F. (1991) Evidence that hydrogen peroxide blocks hormone-sensitive cholesterol transport into mitochondria of rat luteal cells. Endocrinology 128, 2958-2966.

Behrman, H.R. \& Preston, S.L. (1989) Luteolytic actions of peroxide in rat ovarian cells. Endocrinology 124, 2895-2900.
Bill, II, C.H. \& Keyes, P.L. (1983) 17ß-estradiol maintains normal function of corpora lutea throughout pseudo-pregnancy in hypophysectomized rabbits. Biology of Reproduction 28, 608-617.

Chance, B., Sies, H. \& Boveris, A. (1979) Hydroperoxide metabolism in mammalian organs. Physiological Reviews 59, 527-605. 
Dharmarajan, A.M., Sueoka, K., Miyazaki, T., Atlas, S.J., Ghodgaonkar, R.B., Dubin, N.H., Zirkin, B.R. \& Wallach, E.E. (1989) Prostaglandins and progesterone secretion in the in vitro perfused pseudopregnant rabbit ovary. Endocrinology 124, [198-1203.

Dharmarajan, A.M., Zanagnoio, V.L., Dasko, L.M., Zirkin, B.R., Ewing, L.L. \& Wallach, E.E. (199l) Estradiol regulation of the rabbit corpus luteum: in vivo and in vitro studies. Endocrinology 128, 2678-2684.

Dharmarajan, A.M., Zanagnolo, V.L., Dasko, L.M., Hardy, M.P. \& Wallach, E.E. (1992) Changes in rabbit corpus luteum progesterone secretion and cellular morphology following unilateral luteectomy or ovariectomy. Biology of Reproduction 46, 251-255.

Dryer, S.E., Dryer, R.L. \& Autor, A.P. (1980) Enhancement of mitochondrial, cyanide-resistant superoxide dismutase in the livers of rats treated with 2,4dinitrophenol. Journal of Biological Chemistry 255, $1054-1057$.

Dubin, N.H., Ghodgaonkar, R.B. \& King, T.M. (1979) Role of prostaglandin production in spontaneous and oxytocin-induced uterine contractile activity in in vitro pregnant rat uteri. Endocrinology 105, 47-51.

Freeman, B.A. \& Crapo, J.D. (1982) Free radicals and tissue injury. Laboratory Investigation 47, 412 426 .

Fridovich, I. (1986) Biological effects of the superoxide radical. Archives of Biochemistry and Biophysics 247, $1-11$.

Gatzuli, E., Aten, R.F. \& Behrman, H.R. (1991) Inhibition of gonadotropin action and progesterone synthesis by xanthine oxidase in rat luteal cells. Endocrinology 128, 2253-2258.

Hemler, M.D., Cook, H.W. \& Lands, W.E. (1979) Prostaglandin biosynthesis can be triggered by lipid peroxides. Archives of Biochemistry and Biophysics 193, 340-345.

Holt, J.A. (1989) Regulation of progesterone production in the rabbit corpus luteum. Biology of Reproduction 40, 201-208.

Laloraya, M., Kumar, G.P. \& Laloraya, M.M. (1988) Changes in the levels of superoxide anion radical and superoxide dismutase during the estrous cycle of Ratlus norvegicus and induction of superoxide dis- mutase in rat ovary by lutropin. Biochemical and Biophysical Research Communications 157, 146-153.

Lowry, O.H., Rosenbrough, N.J., Farr, A.L. \& Randall, R.J. (I951) Protein measurement with the Folin phenol reagent. Journal of Biological Chemistry 193, $265-275$.

Miyazaki, T., Sueoka, K., Dharmarajan, A.M., Atlas, S.J., Bulkley, G.B. \& Wallach, E.E. (1991) Effect of inhibition of oxygen free radical on ovulation and progesterone production by the in-vitro perfused rabbit ovary. Journal of Reproduction and Fertility 91, 207-212.

Oberley, L.W. \& Spitz, D.R. (1984) Assay of superoxide dismutase activity in tumor tissue. Methods in Enzymology 105, 457-464.

Ohkawa, H., Ohishi, N. \& Yagi, K. (1979) Assay for lipid peroxides in animal tissues by thiobarbituric acid reaction. Analytical Biochemistry 95, 351-358.

Parente, L. (1982) Study on the effect of superoxide dismutase on arachidonic acid metabolism. Prostaglandins 23, 725-730.

Riley, J.C.M. \& Behrman, H.R. (1991) In vivo generation of hydrogen peroxide in the rat corpus luteum during luteolysis. Endocrinology 128, 17491753.

Sawada, M. \& Carlson, J.C. (1985) Association of lipid peroxidation during luteal regression in the rat and natural aging in the rotifer. Experimental Gerontology 20, $179-186$.

Sawada, M. \& Carlson, J.C. (1989) Superoxide radical production in plasma membrane samples from regressing rat corpora lutea. Canadian Journal of Physiology and Pharmacology 67, 465-471.

Sawada, M. \& Carlson, J.D. (I991) Rapid plasma membrane changes in superoxide radical formation, fluidity, and phospholipase $\mathrm{A}_{2}$ activity in the corpus luteum of the rat during the induction of luteolysis. Endocrinology 128, 2992-2997.

Sinet, P.-M. \& Garber, P. (198I) Inactivation of the human $\mathrm{CuZn}$ superoxide dismutase during exposure to $\mathrm{O}_{2}{ }^{-}$and $\mathrm{H}_{2} \mathrm{O}_{2}$. Archives of Biochemistry and Biophysics 212, $411-416$.

Weiss, S.J. (1986) Oxygen, ischemia and inflammation. Acta Physiologica Scandinavica Supplementum 548, 937.

Received 22 July 1991 